\title{
SECONDARY NOMINATIONS OF INDEFINITE QUANTITY \\ IN THE ENGLISH JOURNALISTIC DISCOURSE: TYPOLOGICAL FEATURES
}

\author{
Anna Zinchenko \\ Lecturer, Sumy State University, Ukraine \\ annascent@gmail.com, orcid.org/0000-0002-5672-2331
}

\section{Summary}

The study highlights the urgent issue of indefinite quantity linguistic representation in the English journalistic discourse. "Indefinite quantity secondary nomination" is identified as a secondary nominative creation that actualizes the quantitative feature of the primal nomination meaning, and transposes it to the object through metaphor and metonymy/synecdoche.

The investigation defines the basic patterns of originating for secondary nominations of indefinite quantity in journalistic discourse. The first and most productive, through the metaphor, is motivated by the quantitative similarity between the objects of two different domains. The second and less representative, through the metonymy (synecdoche), is implied by quantitative similarity within the only one domain.

This study attempts to describe the typological features of secondary nominations of indefinite quantity in the English journalistic texts. Based on the semantic, stylistic and contextual analysis, the investigation separates three complex types of images, used for metaphorical transfer: phenomena of nature (including fauna, flora, atmosphere, landscape and celestial bodies), humanmade objects and myth/fable entities. The metonymic transfer uses mostly the transfer based on the spatial and quantitative characteristics. The type of metonymy includes the synecdoche-based transfer of body part images onto an assemblage of objects.

Keywords: media, quantitative features, metaphor, metonymy, transfer by association.

\section{DOI: https://doi.org/10.23856/3816}

\section{Introduction}

The idea of massive information awareness and accessibility forms the agenda of modern society. Obtaining information, its processing and differentiation of true/false messages have already become an urgent issue as well. Thus, communicative impact on the collective consciousness through the media has become one of the most controversial issues.

Scientific investigations of speech manipulation in media discover new sides of epistemic categories, seemed to have been already thoroughly investigated. Today people regularly face numerous facts and statistics as well as manipulation with it through the media. That alone makes subjective the scientific investigations of quantity linguistic representation in journalistic texts.

The category of quantity is one of the basic epistemic categories and has given rise to numerous scientific investigations since the times of Aristotle. Numerous domestic and foreign researchers have studied the linguistic side of the category, that now has been resting on works of V. Akulenko, L. Chesnokova, N. Klymenko V. Panfilov, O. Semenenko, S. Shvachko, O. Yehorova.

The linguistic category of quantity is usually described through the notions of small/ large quantity and definite/approximate/indefinite quantity. However, unlike definite and approximate quantity, linguistic research has yet to deal with the indefinite one: in the course 
of communication as speakers tend to make the speech expressive, they use different secondary nominations of quantity. In the field of media, it has crucial meaning for the whole text perception, affecting the society mind. That defines the subject area of the study: secondary nominations of indefinite quantity in the English journalistic discourse; the specific topic is their typological features.

The purpose of the study is to determine the typological peculiarities of secondary nominations of indefinite quantity in the journalistic discourse. The tasks of the study comprise:1) identification of "secondary nomination of indefinite quantity"; 2) defining basic patterns of their production; 3 ) describe the typological features of the indefinite quantity secondary nominations in the journalistic discourse. To perform the tasks of the study, we turn to the identification and interpretation of indefinite quantity secondary nominations in the English journalistic discourse through the methods of semantic, stylistic and contextual analysis, description and thematic classification.

\section{Theoretical background}

Despite the significant number of linguistic investigations (E. Aznaurova, A. Bekbalayev, V. Hak, O. Kubryakova, O. Taranenko, V. Teliia), the "secondary nomination" phenomenon still has not received a common definition. W. Teliia considers the secondary lexical nomination to be reduced to a simple use of nominations already available in the language, but in a new naming function (Teliia, 1977). V. Hak sees a secondary nomination as the adaptation of the same word form for different functions (Hak, 1977).

This study considers secondary nominations as alternative names to the indefinite quantity phenomena, so we agree with $\mathrm{O}$. Taranenko, that a secondary nomination means naming an object otherwise, however, differently motivated and with a specific purpose (e.g. usage of metaphor/metonymy/periphrasis) or as a transformation of the previous object naming (Taranenko, 2002).

Indeed, secondary nominations of indefinite quantity appear out of speaker's communicative intention as a "substitute" name for quantitatives (words naming quantity) with the semantics of numeral uncertainty. However, as human thinking is initially metaphorical and language functioning corresponds to metaphorical principles (Lakoff, 2004), we believe that secondary indefinite quantitatives are created not only for the metaphor/metonymy sake, as O. Taranenko sets it, but are figurative initially.

In this study, we define a secondary nomination of indefinite quantity as the name of an object/process of the reality, which in its meaning has specific characteristics of indefinite small/large quantitative, created by associations through metaphorization or metonymization, on the purpose of conveying speaker's pragmatic-emotional reaction to a certain amount of the substance etc.

The process of secondary naming has gained overall interest in recent decades, since the introduction of Conceptual Metaphor Theory (G. Lakoff, M. Johnson). According to T. Hobbes, the process of secondary naming is primarily based on the name transference (Hobbes, 1994) a phenomenon is named by the title of another one, motivated by the similarity insight between two different phenomena or their qualities, however, having almost nothing in common in reality and belonging to different classification groups.

Basic processes of secondary naming are usually of metaphorical or metonymical nature. Unlike metaphor, being examined in the abundance of related researches, metonymy itself has been considered for a long time as a by-side product of the latter. However, the cognitivists 
separated them, that is quite logical as in metaphor, we find separate domains, whereas, in metonymy, there is only one domain involved (Diez Velasco, 2001).

In this study, we consider the mechanism of indefinite quantity secondary naming in the journalistic discourse based on the interaction of two criteria: origin and transfer direction. Given that, we describe typological features of the indefinite quantity secondary names, which expand the repertoire of expressive means of publicists.

\section{Typological features of secondary quantitatives}

English journalistic discourse is a vivid example of secondary quantitatives usage through metaphors and metonymies for conveying information, as well as making a social and psychological impact on the mass audience. There are several types of indefinite quantity secondary nominations in the English journalistic discourse, depending on the metaphorical and metonymical transfer.

Secondary quantitatives of metaphorical nature include the following types, originated due to phenomena of:

1) Nature, based on transferring the features of various natural objects and phenomena onto a certain amount of the substance. This study shows this type to be the most productive. It sounds logical as the language reflects human experiences metaphorically, and nature is a permanent resource for the metaphorical images (Meisner, 1995).

Due to natural phenomena diversity, we outlined the following kinds of secondary nominations of indefinite quantity based on nature-oriented metaphors. Considering the specifics of indefinite quantitatives, however, the following types of secondary nominations very often involve notions of groups or processes, their characteristics, indicating indefinite amount:

a. fauna: 'Not a mask in sight': thousands flock to Yellowstone as park reopens (The Guardian, 2020), "Get off me, get off me!" a woman screamed as at least three federal agents swarmed over her, shoving her to the street and holding her down (USA Today, 2020), Rights groups and opposition criticize PM for labelling migrants a 'swarm of people', and UN representative says UK is not dealing responsibly with crisis (The Guardian, 2015);

b. flora: Hope Solo calls Sweden 'bunch of cowards' after USA falter at Olympics (The Guardian, 2016), MSF brands humanitarian summit 'a fig-leaf of good intentions' as it pulls out (The Guardian, 2016), Books; Harvesting the trees of knowledge (The Independent, 1998), Patrick Cockburn: Greece has an overgrown and expensive state machine (The Independent, 2012).

c. atmosphere: Lift this cloud of secrecy (The Guardian, 2009), There was a flurry of activity in and around Salisbury on Monday afternoon (The Guardian, 2018), Jennifer Lawrence and Meryl Streep blast Harvey Weinstein for use of statements in lawsuit (The Guardian, 2018);

d. landscape: James Daley: Beware the forest of 'green'schemes (The Independent, 2007), Brazil coronavirus: medics fear official tally ignores 'a mountain of deaths'(The Guardian, 2020), Between a rock and a mountain of debt (The Guardian, 2020);

$e$. celestial bodies: The hologram features a myriad of lights that swarm like fireflies to form into a 3-D image of Floyd, with his name depicted around his image (USA Today, 2020); To the moon and back with the eastern curlew (The Guardian, 2019), UK universities face cash black hole amid coronavirus crisis (The Guardian, 2020);

2) Humanmade objects, based on transferring the quantitative characteristics of manmade objects: London needs homes, not towers of 'safe-deposit boxes' (The Guardian, 2015), The World Health Organization (WHO) says there is a "window of opportunity" to stop the deadly new coronavirus becoming a broader global crisis (BBC News, 2020), French and 
Saunders: A farewell bucket of swill (The Guardian, 2007), A Barrel of Trouble (The New York Times, 2013);

3) Myth and fable. As myths and fables myths are not intended to be taken literally, being metaphorical attempts to describe reality (Malan, 2016), some secondary quantitatives originated from them: Kubrick: a marketing odyssey (The Guardian, 2007), Enlarging Europe: Hot air billows in the Tower of Babel (The Independent, 1997), Henry Kissinger: A diplomatic colossus who is still a key influence in US amid Syria crisis (The Independent, 2013).

Secondary quantitatives of metonymical nature are presented solely by the local type. Originated due to the associative connection between certain spatial concepts, as localization is perceived as a domain, in which a speaker distinguishes subclass/members. It is the most frequent type of metonymic indefinite quantitatives, being necessary to avoid tautologies in a journalistic text. E.g. UK not doing enough to stop coronavirus second wave, warns BMA chief (The Independent, 2020), Brazil confirms nearly 70,000 coronavirus cases in new national daily record (The Guardian, 2020), White House pushed to include \$1.75 billion for new FBI headquarters in GOP pandemic aid bill (USA Today, 2020), I saw the entire piazza went in the direction next to the screen to escape, all in a panic (The Guardian, 2017).

Secondary indefinite quantitatives of metonymical nature also include a group of those, originated from a synecdoche. We agree with Z. Kövecses (Kövecses, 2010), who considers synecdoche to be another metonymic variant. It is created by transferring the object characteristics within one domain as well; however, synecdoche is made by the principle "a part represents the whole" and vice versa.

The corpus of journalistic texts demonstrated that the type "body part - people" is the most productive. E.g.: US academics feel the invisible hand of politicians and big agriculture (The Guardian, 2019), Today's fans recognize Borgia as the face and voice of the NBA's replay center in Secaucus, New Jersey where reviews are conducted along with referees on the court (USA Today, 2020), The stately homes built on the back of slaves (The Independent, 2013).

Here we also include the word "voice", considering it related to the human body. The analyzed journalistic texts demonstrated that this lexeme is often used as the secondary nomination of indefinitely large quantity: Voices of Protest: Desperation, Rage, Hope (USA Today, 2020), Lena Dunham: Could she be the voice of a generation? (The Independent, 2012), Andrea Bocelli: Voice of the people (The Independent, 2008).

\section{Conclusion}

The study of secondary nominations of indefinite quantity proves that the indefinite quantity actualizes in the English language not only as an abstract entity. Indefinite quantity as a sensual image gives origin to secondary quantitatives through the metaphorical and metonymical transfers. Investigation of the journalistic texts has demonstrated the metaphor to be the most productive way for indefinite-quantity secondary naming.

Thus, indefinite qualitative characteristics of natural and humanmade objects and phenomena associate with other real-life notions through different kinds of metaphors may cause some strong emotions, that is of help in journalism. Types of secondary indefinite quantitatives, though, considerably fewer appeared in metonymy and synecdoche, mainly appeal to assemblage/consolidated force, that perfectly contributes to concision of a journalistic text without loss of manipulative effect. 
The given typology of indefinite quantity secondary nominations is now of a universal or an exhaustive character but rather directs to further investigation into the expressive, manipulative and stylistic potential of quantitatives in the English journalistic texts.

\section{References}

Díez Velasco, O. I. (2001). Metaphor, metonymy, and image-schemas: an analysis of conceptual interaction patterns. Journal of English Studies, 3-2. 47-63.

Hak, W. H. (1977). K tipologii lingvisticheskih nominatsyi // Yazykovaya nominatsyya. Obshchiye voprosy. [Problems of linguistic nominations typology // Linguistic nomination. General studies.]. Moscow: Nauka. [in Russian]

Hobbes, T. (1994). Of the consequence or train of imaginations. The philosophy of mind. Cambridge (Mass.) : MIT Press.

Kövecses, Z. (2010). Metaphor: a Practical Introduction (2nd Ed). New York: Oxford University Press.

Lakoff, J. (2004). Metafory, kotorymi my zhivem. [Metaphors we live by]. Moscow: Editorial URSS. [in Russian]

Malan, G. (2016). Myth as metaphor. Pretoria: University of Pretoria Press.

Meisner, M. S. (1995). Metaphors of Nature. The Trumpeter, 12-1. 11-18.

Taranenko, O. O. (2002). Nominatsyya // Ukrayintska mowa. Entsyklopediya [Nomination // The Ukrainian language. Encyclopedia]. Kyiv: Ukr. encykl. [in Ukraininan]

Teliia, W. N. (1977). Wtorichnaya nominatsyya i yeho widy [Secondary nomination and its types]. Moscow: Nauka. [in Russian] 